\title{
Tessier 30 Facial Cleft Associated with Complete Duplication of Tongue: A Rare Entity
}

\author{
Jayanto Tapadar ${ }^{1}$, Preeti Tiwari ${ }^{2 *}$ \\ ${ }^{1}$ Plastic Surgery, Smayan Hospital, Varanasi, India \\ ${ }^{2}$ Trauma Centre, Institute of Medical Sciences, Banaras Hindu University, Varanasi, India \\ Email: tapadarjk@hotmail.com,
}

Received 4 March 2015; accepted 23 March 2015; published 27 March 2015

Copyright (C) 2015 by authors and Scientific Research Publishing Inc.

This work is licensed under the Creative Commons Attribution International License (CC BY). http://creativecommons.org/licenses/by/4.0/

(c) () Open Access

\begin{abstract}
Background: Median cleft of mandible and lower lip is a rare anomaly [1]. Only a few cases have been reported in literature with different variations till now. Herein we report a patient with Tessier 30 cleft associated with complete duplication of tongue. Aim: We herein report this rare variant as it posed special challenges for its management by virtue of its uniqueness, late presentation and limited affordability of patient for standard treatment. Case Report: A 12 years old female reported to us with a chief complaint of a midline gap in the lower lip and mandible since birth. On examination under anaesthesia, we found that tongue was not bifid. There was complete duplication of the tongue. The case was planned for staged repair of the defect. In the same sitting, a repair of the soft tissues in the midline was performed. Conclusion: There are no specific guidelines in literature for management of such cases. This makes all these cases worth for reporting in order to guide treating surgeons.
\end{abstract}

\section{Keywords}

Facial Cleft, Duplication of Tongue, Tessier 30 Cleft, Bifid Tongue

\section{Introduction}

Median cleft of mandible and lower lip is a rare anomaly [1]. Tessier published a detailed description of the classification of craniofacial clefts in 1976 [2]. Often serious asymmetry exists and multiple areas of the face are affected simultaneous. Further there is a continued restricted growth of affected tissues after birth. Because of this, the deformities at birth can become more obvious over the years. This results in a clear three-dimensional

${ }^{*}$ Corresponding author.

How to cite this paper: Tapadar, J. and Tiwari, P. (2015) Tessier 30 Facial Cleft Associated with Complete Duplication of Tongue: A Rare Entity. International Journal of Otolaryngology and Head \& Neck Surgery, 4, 169-172. 
underdevelopment of hard and soft tissues of the orbit, maxilla, zygoma, nose and malar region. Couronne in 1819, first reported a case of midline mandibular cleft. Since then 66 cases have been reported worldwide till 2007 [3]. Only a few cases have been reported in literature with different variations till now. Herein we report a patient with Tessier 30 cleft associated with complete duplication of tongue.

\section{Case Report}

A 12 years old female reported to us with a chief complaint of a midline gap in the lower lip and mandible since birth (Figure 1). The child was psychologically depressed due to his appearance. The child was born as the first child to unrelated healthy parents at term by spontaneous vaginal delivery. There was no history of any relevant abnormalities in the family. His medical history was unremarkable, and she appeared as a healthy young girl of normal intelligence \& neurocognitive development. On examination there was a midline cleft of mandible and lower lip. Further this was associated with bifid tongue. Orthopentomogram showed a bony defect in the midline of the mandible. Complete blood count and other haematological parameters were normal. After fitness for anaesthesia the patient was taken for examination under general anaesthesia. On examination under anaesthesia, we found that tongue was not bifid. There was complete duplication of the tongue (Figure 2). The case was planned for staged repair of the defect. In the same sitting a repair of the soft tissues in the midline was performed (Figure 3 and Figure 4). No attempt was made to reconstruct the lower lip and tongue at this stage. The patient is currently being followed-up for assessment of the mandibular growth and midline union, assessment of dentition and planned for further management with secondary repair of the lower lip and repair of the duplicated tongue at a later stage.

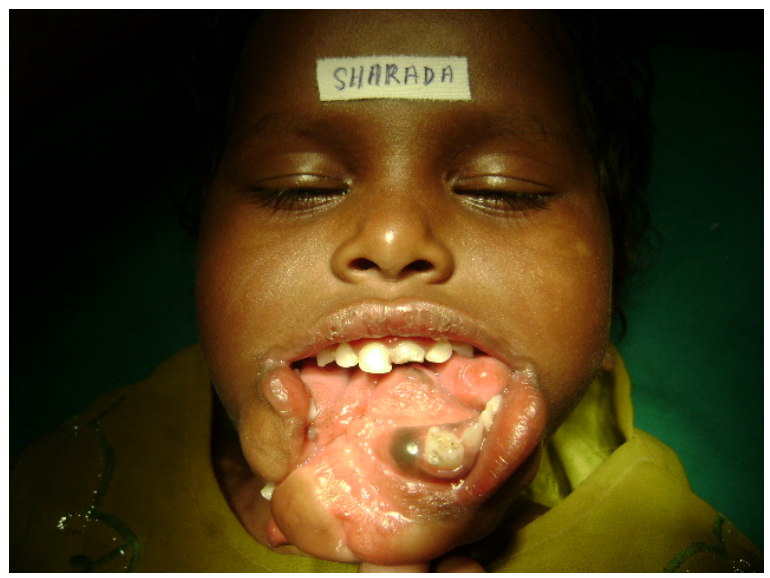

Figure 1. Tessier 30 cleft.

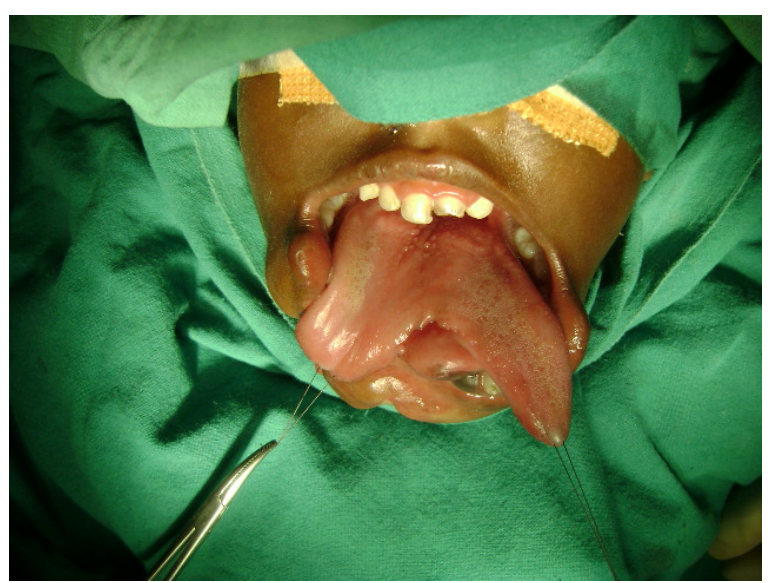

Figure 2. Examination under anesthesia showing complete duplication of tongue. 


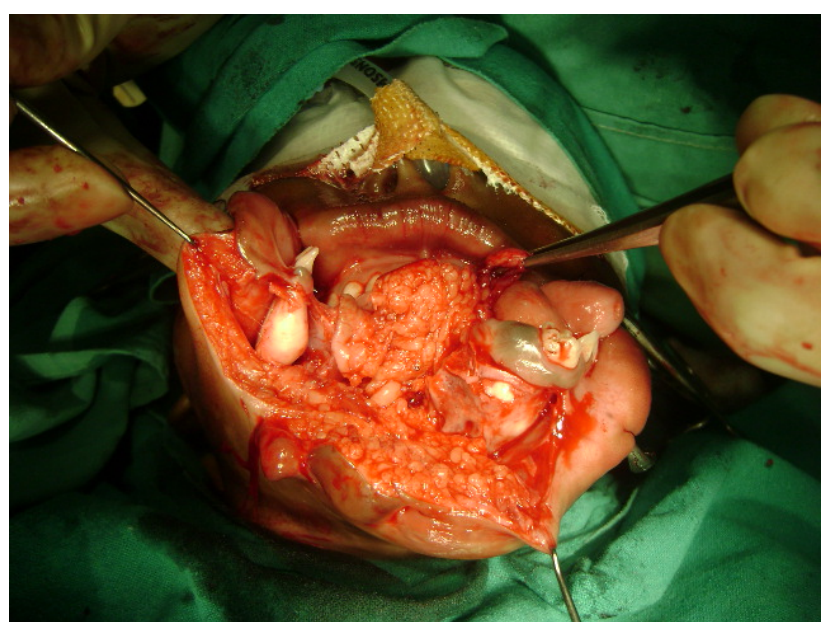

Figure 3. Intraop image of closure of cleft.

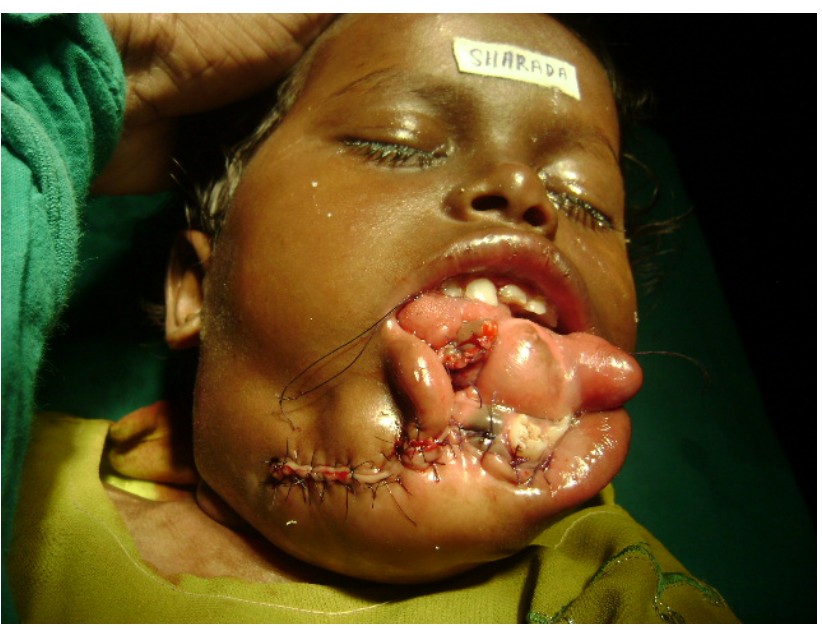

Figure 4. Immediate post op image after first stage of closure.

\section{Discussion}

Midline facial clefts are extremely rare congenital deformities. Their precise incidence in the population is unknown with reported incidence of [1]. Tessier described an anatomical classification system, in which number is assigned to each craniofacial cleft on the basis of its position relative to sagittal midline $\&$ the orbit [2]. The first report of midline mandibular cleft was reported by Couronne in 1819, since then 66 cases have been reported worldwide till 2007 [3]. The extent of cleft is variable and extent is variable. In the more severe forms, it may extend into the bony mandibular symphysis. In some cases, the neck structures like the hyoid bone, thyroid cartilage and even the strap muscles of the front of the neck may be involved. The anterior portion of the tongue may be bifid [4]. The extent of bifid tongue is also variable and is usually associated with ankyloglossia [5] [6]. The etiopathogenesis of atypical craniofacial clefts is still unclear. Typical cleft lip and palate result from a failure of union of the frontonasal process with the lateral maxillary prominences at about 3 - 5 weeks of gestation. Theories regarding the pathogenesis of these clefts include the failure in mesodermal migration and disruption of neural crest cell development along normal fusion planes in the developing facial skeleton. CT scans with threedimensional reconstruction on the visible components of craniofacial clefts do not necessarily reflect the true extent of the cleft [6] [7]. The actual timing of corrections is often based on severity and nature of the deformity with consideration of functional problems, growth, and mental burden for the patient and wishes of patients and/or parents. However, previous conducted studies show that the intensity of the psychological burden for patients caused by the deformity is not directly related to the severity of the deformity. The case reported here had 
midline cleft of the lower lip with cleft of the mandible, associated with complete duplication of the tongue. There was no ankyloglossia and structures were completely duplicated upto posterior part. Although Britto et al. reported a case of double tongue with cleft palate, there has been no case report with Tessier 30 cleft with complete duplication of the tongue [7]. The case was taken up for staged repair. In the first stage, the two halves of the mandible were approximated. The treatment, as advocated by Armstrong and Waterhouse [8] is to tackle the condition in a staged manner. In the first stage, soft tissue correction including Z-plasty in chin, lip and neck is performed. In our case repair was performed after extensive midline mobilisation of soft tissues. Secondary repair of the lower lip to improve the cosmetic appearance and fusion of the two halves of the tongue will be taken up at subsequent stages.

Mandible reconstruction is done after 10 years of age to minimize damage to the developing tooth buds. However, earlier treatment may be indicated when the segments are hypermobile, causing respiratory or feeding difficulty [8].

\section{Conclusion}

The findings of this report demonstrate that this rare variant poses special challenges for its management by virtue of its uniqueness, late presentation and limited affordability of patient for standard treatment. There are no specific guidelines in literature for management of such cases. This makes all these cases worth for reporting in order to guide treating surgeons.

\section{References}

[1] Kawamoto Jr., H.K. (1990) Rare Craniofacial Clefts. In: McCarthy, J.G., Ed., Plastic Surgery, Vol. 4, W.B. Saunders, Philadelphia, 2940.

[2] Tessier, P. (1976) Anatomical Classification of Facial, Cranio-Facial and Latero-Facial Clefts. Journal of Maxillofacial Surgery, 4, 69-70. http://dx.doi.org/10.1016/S0301-0503(76)80013-6

[3] Senan, M., Padmakumar, G. and Jisha, K.T. (2007) Tessier Number 30. Indian Journal of Plastic Surgery, 40, 57-60. http://dx.doi.org/10.4103/0970-0358.32666

[4] Oostrom, C.A., Vermeij-Keers, C., Gilbert, P.M. and Van Der Meulen, J.C. (1996) Median Cleft of Lower Lip and Mandible: Case Reports, a New Embryologic Hypothesis and Subdivision. Plastic \& Reconstructive Surgery, 97, 313320. http://dx.doi.org/10.1097/00006534-199602000-00006

[5] Chidzonga, M.M., Lopez Perez, V.M. and Mzezewa, S. (1996) Treatment of Median Cleft of the Lower Lip, Mandible, and Bifid Tongue with Ankyloglossia: A Case Report. International Journal of Oral and Maxillofacial Surgery, 25, 272-273. http://dx.doi.org/10.1016/S0901-5027(06)80054-8

[6] Tiwari, V.K. (2000) Median Cleft of Lower Lip and Mandible: A Case Report. Indian Journal of Plastic Surgery, 33, 98-100.

[7] Britto, J.A., Ragoowansi, R.H. and Sommerlad, B.C. (2000) Double Tongue, Intraoral Anomalies and Cleft PalateCase Reports and a Discussion of Developmental Pathology. Cleft Palate-Craniofacial Journal, 37, 410-415. http://dx.doi.org/10.1597/1545-1569(2000)037<0410:DTIAAC>2.3.CO;2

[8] Armstrong, A. and Waterhouse, N. (1996) Tessier 30 Median Mandibular Cleft: Case Report and Literature Review. British Journal of Plastic Surgery, 49, 536-538. http://dx.doi.org/10.1016/S0007-1226(96)90130-7 